\title{
Estudo longitudinal e quimioterapia específica em crianças, com doença de Chagas crônica, residentes em área de baixa endemicidade da República Argentina
}

\author{
Longitudinal study and specific chemotherapy in children with chronic Chagas' disease, \\ residing in a low endemicity area of Argentina
}

\author{
Mirtha L. Streiger ${ }^{1}$, Mónica L. del Barco ${ }^{1}$, Diana L. Fabbro ${ }^{1}$, Enrique D. Arias ${ }^{1}$ \\ e Norberto A. Amicone ${ }^{1}$
}

\begin{abstract}
RESUMO
Apresenta-se a avaliação clinicoepidemiológica de 95 crianças chagásicas crônicas em idades entre 1 e 14 anos moradoras de Santa Fé, Argentina, não tratadas e tratadas com nifurtimox ou benznidazol, com acompanhamento de até 24 anos. Todas tinham vários antecedentes de risco para transmissão do Trypanosoma cruzi: vetorial, congênito e/ou transfusão sangüínea. 0 diagnóstico da infecção foi feito através de sorologia convencional. 0 exame clínico foi complementado por eletrocardiograma, radiografias de tórax e, análise de sangue e urina para avaliação das funções hepáticas. № póstratamento, utilizaram-se técnicas idênticas às do diagnóstico, sendo que 33 crianças tiveram, também, avaliação parasitológica. Dentre 24 crianças não tratadas, 14 foram controlados por 8 a 24 anos e mantiveram sorologia positiva e 0 estado clínico inicial. Das 71 crianças tratadas, 49 tiveram acompanhamento de 4 a 24 anos: 14 mantiveram anticorpos anti-Trypanosoma cruzi; 6 resultados discordantes e 29 negativaram a sorologia. Destas, 9 apresentaram oscilações sorológicas, antes da negativação definitiva. A mediana do tempo de negativação pós-tratamento foi, respectivamente, de 3,5 e 8 anos para crianças de 1 a 6 e 7 a 14 anos. A percentagem de soronegativos diminuiu com a idade em que se medicou, desde $75 \%$ em $\leq 4$ anos até $43 \%$ em $\geq 9$ anos. A intolerância ao tratamento foi de 3,8\%. Nenhuma criança modificou seu estado clínico nesta observação.
\end{abstract}

Palavras-chaves: Doença de Chagas crônica. Crianças. Epidemiologia. Tratamento específico. Seguimento.

\begin{abstract}
Clinical and epidemiological results of 95 treated and untreated chronic chagasic children, with an up to 24 years follow-up period are presented. This population studied in the 1/14 age bracket, residing in Santa Fe city, Argentina, was diagn osed through Chagas- specific conventional serologic reactions. Clinical examination was supplemented with electrocardiogram, chest X-rays, and blood and urine tests for evaluating hepatic function. The drugs employed were nifurtimox or benznidazole. In post treatment period xenodiagnosis was made in 33 patients. Regarding Trypanosoma cruzi transmission, the studied individuals presented multi-risk antecedents: vectorial, congenital and/or blood transfusion. Among 24 untreated children 14 were controlled during 8/24 years: all this patients maintained the initial antibody concentration and clinical status. From 71 treated patients 49 were followed-up 4/24 years: 14 remained positive, 6 presented dubious results, and 29 showed final non-reactive results. 9 of this presented sometimes oscilating results. In 1/6 age bracket children, the serology turned negative after 3.5 years (median) once the treatment was finished, while patients treated in the 7/14 age bracket, the median of negativization was 8 years. 3.8\% did not tolerate the drug. None of the groups changed their clinical condition. The untreated children did not change the serology. The percentage of treated children presenting negative serological results decrease according to the age when treatment was given: $75 \%$ became negative when treated at $\leq 4$ years old and $43 \%$ when treated at $\geq 9$ years old.
\end{abstract}

Key-words: Chagas' disease. Chronic phase. Children. Epidemiology. Specific treatment. Follow-up.

1. Centro de Investigaciones sobre Endemias Nacionales, Facultad de Bioquímica y Ciencias Biológicas, Universidad Nacional del Litoral, Santa Fe, Argentina.

Financiado por UNL para Proyectos CAI+D.

Address to: Dra Mirtha L. Streiger. Paraje El Pozo. Ciudad Universitaria, Casilla Postale 3000, Santa Fe, Argentina.

e-mail: streiger@ fbcb.unl.edu.ar

Recebido para publicação em 10/09/2002

Aceito em 5/7/2004 
Na doença de Chagas merecem importância sanitária as vias de transmissão vetorial, transfusional e transplacentária e por transplante de órgãos. Por quaisquer das vias que se tenha adquirido a infecção, a mesma apresenta sucessivamente, em geral, uma fase aguda (aparente ou inaparente) e uma fase crônica (indeterminada assintomática, ou sintomática tardia cardíaca e/ou digestiva). Assim, como é importante o seguimento clínico dos infectados, por longo período, para conhecer a história natural desta enfermidade, também é importante 0 seguimento prolongado em pacientes que tenham recebido quimioterapia tripanocida ${ }^{22} 3340$.

Nos anos 1982 e 1983 não existiam recomendações sobre 0 tratamento em chagásicos crônicos e a experiência em adultos mostrava que estes, pós-tratamento, continuavam sorológicamente positivos ${ }^{511}$. Em 1983, as Normas em Argentina indicavam que a infecção chagásica só tinha possibilidade de cura quando se fazia 0 tratamento antiparasitário específico no início da mesma (fase aguda) ${ }^{24}$. Porém, nos recém-nascidos (RN) com infecção transplacentária tem-se observado que 0 tratamento produz negativação sorológica e parasitológica, ainda nos tratamentos iniciados após os dois anos de ter sido diagnosticada a infecção, já superada a fase aguda ${ }^{1326} 3438$.

Entre as décadas de 1970 e 1980, começamos os estudos epidemiológicos transversais e longitudinais sobre infecção chagásica em amostragem de adultos ( setores laborais, grávidas) e de crianças ( ao ingressar na escola ${ }^{36}$, recém-nascidos (RN) de mães chagásicas e filhos - não RN- de mães infetadas) residentes em área de baixa endemicidade (cidade de Santa Fé, Argentina). Algumas crianças entre 1 e 14 anos de idade, provenientes desses estudos e outras, por demanda espontânea, foram controladas longitudinalmente mediante exames clínicos, sorológicos e parasitológicos. Num grupo de crianças se fez tratamento antiparasitário especifico. À luz dos conhecimentos existentes e surgidos no transcurso daqueles anos, realizou-se um estudo de coorte a respeito do tratamento antiparasitário em crianças. Em 1993, apresentamos os primeiros resultados da resposta à quimioterapia especíica em crianças com infecção chagásica que não estavam no período agudo. Nossos resultados mostraram que $63 \%$ das crianças infectadas negativaram sua sorologia (com as mesmas técnicas utilizadas para 0 diagnóstico) três anos e meio após ter finalizado o tratamento específico, administrado entre 30 e 60 dias, e que quanto menor era a idade da criança, mais cedo se obtinham esses resultados ${ }^{16}$.

A partir desse trabalho de nossa equipe (1993) outros autores têm publicado estudos de avaliação da quimioterapia em crianças ${ }^{313} 18$, alguns com desenho de caso-controle randomizado, e com resultados similares. Isto levou a fazer modificações nas normas de atenção ao infectado chagásico na Argentina e por consenso de especialistas sobre as doses recomendadas dos fármacos no Brasil 217242542

0 presente trabalho mostra os resultados do seguimento clínico, sorológico e parasitológico em crianças com infecção chagásica na fase crônica, tratada e não tratada, durante período de até 24 anos.

\section{MATERIAL E MÉTODOS}

Desenho do estudo. Coorte quase experimental. A amostra de 95 crianças com infecção chagásica, iniciada em 1976, provinha de: a) amostragem ao ingresso escolar, b) demanda espontânea, c) filhos (não RN) de mãe chagásica. Todas eram residentes na Cidade de Santa Fé (Argentina) onde não se observa transmissão vetorial, com faixa etária entre 1 e 14 anos (Tabela 1).

Tabela 1 - Distribuição por idade e sexo no início do estudo, da coorte de crianças com infecção chagásica crônica, residentes na cidade de Santa Fé, Argentina (1976-2002).

\begin{tabular}{lccc}
\hline Grupos etários (anos) & Masculino & Feminino & Total \\
\hline 1 a 4 & 9 & 6 & 15 \\
5 a 6 & 11 & 7 & 18 \\
7 a 8 & 5 & 20 & 25 \\
9 a 14 & 13 & 24 & 37 \\
\hline Total & 38 & 57 & 95 \\
\hline
\end{tabular}

Exame clínico. 0 exame clínico foi complementado com eletrocardiograma de 12 derivações (ECG), radiografia de tórax ( $\mathrm{Rx}$ ) e análises clínicas: hemograma, exame de urina e dosagem de uréia e transaminases. Não se realizaram estudos radiológicos nem funcionais do aparelho digestivo.

Anamnese. Além da sintomatologia clínica, avaliaram-se antecedentes migratórios, de transfusões, habitacionais e de sorologia materna.

Reações sorológicas. As reações sorológicas utilizadas foram aglutinação direta $(\mathrm{AD}$ s/c 2-ME), hemoaglutinação indireta (HAI) e imunofluorescência indireta (IFI). Consideraram-se positivas ( $\mathrm{S}^{+}$) titulação $\geq 32^{101535}$. Em alguns soros realizou-se também ELLSA, com 0 kit comercial Chagastest (Laboratório Wierner, Argentina). As amostras de sangue foram obtidas por punção venosa e processadas a duplo cego.

Métodos parasitológicos. Xenodiagnóstico (Xd) : feito com quatro caixas com 10 ninfas de Triatoma infestans, de $3^{\circ}$ estádio cada, na maioria dos casos. Leituras aos 30, 60 e 90 dias $^{1239} .0$ xenodiagnóstico não foi realizado em todos os casos, tendo sido aplicado somente em 38 crianças prétratamento, com média de 3 xenodiagnósticos/criança.

Critérios para definir a infecção crônica: a) reatividade em pelo menos duas das três reações sorológicas com títulos significativos $\left(\geq 32, \mathrm{~S}^{+}\right)$; b) ausência de IgM específica; c) ausência de sinais e sintomas clínicos de infecção aguda. d) Levaram-se em consideração os antecedentes epidemiológicos obtidos na anamnese.

Tratamento. 0 tratamento foi realizado com nifurtimox e benznidazol (Tabela 2), em doses previstas nas Normas Nacionais ou Recomendações 212429 , em esquemas a seguir mencionados. Nifurtimox: $12-15 \mathrm{mg} / \mathrm{kg} / \mathrm{dia}$, durante $45-60$ dias, fracionadas em 2-3 vezes. Benznidazol: $5 \mathrm{mg} / \mathrm{kg} / \mathrm{dia}$, durante 30 dias, fracionadas em 2 vezes. Inicia-se com a metade da dose durante a primeira semana. A droga utilizada foi a disponível no momento. 
Tabela 2 - Distribuição de crianças com infecção chagásica crônica tratadas com nifurtimox ou benznidazol, e não tratadas, segundo a idade ( Santa Fé, Argentina, 1976-2002).

\begin{tabular}{lcccc}
\hline $\begin{array}{l}\text { Grupos etários } \\
\text { (anos) }\end{array}$ & \multicolumn{2}{c}{ Tratadas } & Não tratadas & Total \\
\cline { 2 - 3 } & $\mathrm{Nx}$ & $\mathrm{Bz}$ & & \\
\hline 1 a 6 & 4 & 24 & 5 & 33 \\
7 a 14 & 3 & 40 & 19 & 62 \\
\hline Total & 7 & 64 & 24 & 95 \\
\hline
\end{tabular}

$\mathrm{N} \mathrm{x}=$ nifurtimox; $\mathrm{Bz}=$ benznidazol

Considerações sobre o tratamento e aspectos éticos. No começo 0 critério de seleção dos pacientes para indicar 0 tratamento tripanossomicida foi a detecção do Trypanosoma cruzi no xenodiagnóstico. Logo foi a sorologia francamente positiva em pelo menos duas das três reações ou quando, com anterioridade, se diagnosticou Chagas agudo e por alguma razão não se tratou nessa fase da infecção ${ }^{1934}{ }^{198}$. Orientava-se os pais para comparecer para 0 controle durante a administração da medicação e ao finalizar a mesma. Excluíram-se do grupo tratado duas crianças: uma que retornou temporariamente à zona endêmica e outra que não completou 0 tratamento. Das 24 crianças que não receberam tratamento, 10 não regressaram para fazer 0 controle. Os outros 14 não foram tratados já que em 8 se fez 0 xenodiagnóstico e 0 único positivo foi em uma menina de 14 anos grávida. Os outros 6 foram sorológicamente positivos, mas, nesse momento não haviam evidências da eficácia das drogas tripanossomicidas para a doença de Chagas crônica. Quando se constatou que poderia haver algum benefício, estes pacientes já eram maiores de idade. Por tratar-se de crianças, foi necessário o consentimento dos pais ou responsáveis para ministrar 0 tratamento, informando-lhes sobre as possíveis reações adversas, assim como, seu direito à suspensão e consulta imediata se tivessem reações adversas.

Seguimento. No seguimento, os exames clínicos e de laboratório foram os mesmos que se utilizaram para 0 diagnóstico inicial. Levaram-se em consideração dados recolhidos durante o seguimento, por exemplo: 1) ter transitado ou permanecido em área endêmica, pelo risco de re-infecção via vetorial. 2) 0 número de filhos que as mulheres tiveram, durante 0 tempo de seguimento, pelo risco de transmissão materno fetal. Freqüência dos exames. Mesmo recomendandose aos familiares, para voltar a cada ano, ou citando-os especialmente para 0 controle das crianças, os exames eram realizados, somente, quando elas podiam comparecer ${ }^{37}$.

Análise estatística. Utilizou-se 0 método curvas de vida (Curvas de Kaplan-Meier) para calcular a probabilidade de soroconversão de positivos a negativos $\left(S^{+} \rightarrow S\right.$ ) durante 0 tempo de seguimento, já que a coorte não foi examinada simultaneamente nem por lapsos idênticos de tempo. Para a análise comparativa por faixas etárias, utilizou-se 0 teste de long-rank ou Mantel e Hentzel $\left(\chi^{2}\right)$ e teste de regressão lineal ( Stata) $)^{431}$.

\section{RESULTAD0S}

Antecedentes epidemiológicos e exame clínico. № início do estudo os antecedentes epidemiológicos das crianças infectadas ( sexo, procedência geográfica - migrações desde área endêmicas -, sorologia materna, antecedentes de transfusão e habitacional) se observam na Figura 1. Em geral, 40\% das crianças eram do sexo masculino e na maioria houve migrações, moradia precária e mães soropositivas. Em $81 \%$ das crianças, não se informou a ocorrência previa de transfusão de sangue. Quanto à exposição aos fatores de risco, para 83 crianças com informação completa, 65 (78\%) estiveram expostos a mais de um fator de risco de infecção (Figura 1 e Tabela 3). Em 55,4 (46/83) pode ter ocorrido a infecção tanto por transmissão entomológica como materno-fetal e/ou transfusional.

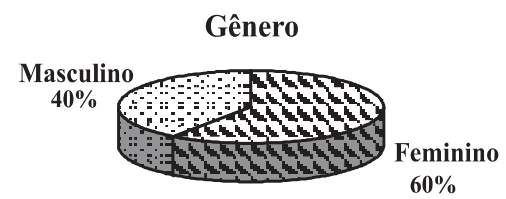

Migrações de áreas endêmicas Mãe $S^{+}$para doença de Chagas
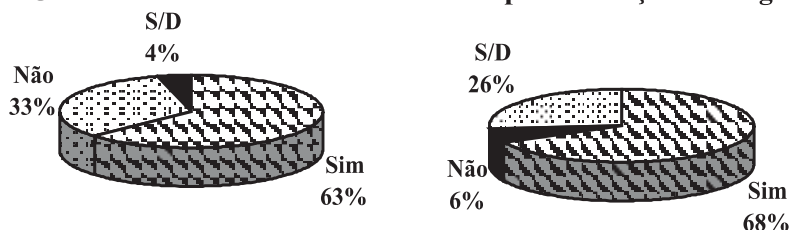

Transfusões

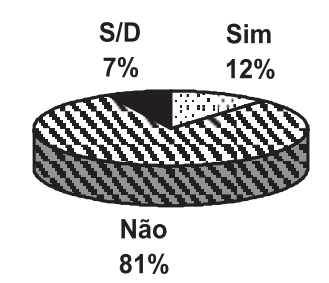

Moradia precária $68 \%$

$\mathrm{S} / \mathrm{D}=$ sem dados

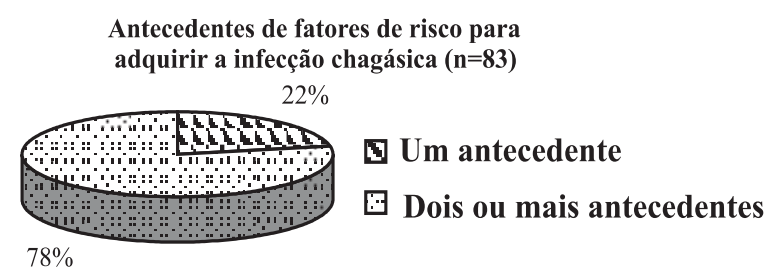

Figura 1 - Dados epidemiológicos de 95 crianças (idade mediana: 8 anos) com infecção chagásica, residentes na Cidade de Santa Fé (Argentina).

Tabela 3 - Freqüência de antecedentes de risco em crianças com infecção chagásica ( Santa Fé, Argentina, 1976-2002).

\begin{tabular}{llr}
\hline Antecedentes & Fatores de risco & Total crianças \\
\hline Sem dados & - & 12 \\
Com 1 antecedente & migração & 1 \\
& mãe S+ & 17 \\
Com 2 antecedentes & migração + mãe S+ & 1 \\
& mãe $S^{+}+$transfusão & 1 \\
& mãe $S^{+}+$moradia precária & 7 \\
& migração + moradia precária & 19 \\
Com 3 antecedentes & migração + transfusão + moradia precária & 3 \\
& mãe $S^{+}+$transfusão + moradia precária & 3 \\
& migração + mãe $S^{+}+$moradia precária & 27 \\
Com 4 antecedentes & migração + mãe S+ transfusão + moradia precária & 4 \\
\hline Total & & 95 \\
\hline
\end{tabular}


Procedência geográfica. Das 95 crianças, 63\% das crianças nasceram e/ou viveram em área endêmica e 31 (33\%) não migraram, mas, exceto uma, suas mães eram $\mathrm{S}^{+}$, e 4 delas também receberam transfusões. Em somente uma criança consta como único antecedente ter vivido em área endêmica, e em 3 a migração associou-se com moradia precária (Tabela 5: Casos 16, 18, 27; Tabela 7: Caso 8).

Infecção materna. As mães de 65 (68\%) crianças apresentavam sorologia positiva para doença de Chagas. Das 24 crianças com antecedentes de infecção materna, sem antecedentes migratórios nem transfusões, 17 viveram em casa de alvenaria, em zona não endêmica e poder-se-ia especular que sua infecção ocorreu por via materno-fetal. Mas, ainda assim, e apesar da minuciosidade com que foi realizada a anamnese, não podemos afirmar qual tenha sido a porta de entrada do parasita.

0 desconhecimento da sorologia materna em $26 \%$ das crianças deve-se a: 1) crianças adotadas; 2) provenientes de lares-escolas, 3) mães falecidas, ou 4) por razões laborais ou econômicas as mães não os puderam acompanhar nem comparecer ao controle.

Transfusões. As 11 crianças que receberam transfusões apresentaram, ainda, outros antecedentes de risco de infecção: migratórios de zona endêmica e moradia precária e/ou suas mães estavam infectadas, como se observa nas Tabelas 5, 7, 9 e 11.
Moradia precária. A precariedade, atual ou anterior, em $69 \%$ das habitações, evidencia mais uma vez a relação desta infecção com a pobreza. Nesta coorte nunca a vivenda precária se apresentou como único antecedente, sempre esteve associada a um dos outros três: área endêmica, madre infectada e/ou transfusão.

Via de infecção. Salvo poucos casos, não foi possível estabelecer qual foi a via de infecção.

Nas crianças que nos antecedentes apresentaram uma via de infecção provável, não se observou associação entre a forma adquirida e a negativação sorológica ( $p>0,5)$.

Exame clínico. № início do estudo, o ECG mostrou bloqueio incompleto do ramo direito, em duas crianças e um bloqueio auriculoventricular de $1^{\circ}$ grau. Quatro crianças apresentaram atraso escolar (oligofrenia?) (Tabela 5: Caso 19; Tabela 11: Caso 2 e duas crianças sem seguimento suficiente) e outro começou a andar aos 2 anos ( Tabela 5: Caso 3). Uma criança (Tabela 5: Caso 4) sofria de convulsões febris a partir de um ano de vida. Esteve medicada com fenobarbital $(0,015 \mathrm{~g})$ até os 4 anos de idade e não voltou a apresentar esses sintomas. Seu desenvolvimento psicomotor atual é normal. Várias crianças sofriam de parasitoses intestinais, principalmente Giardia lamblia e Entamoeba sp.

Tratamento e seguimento. Das 95 crianças, 71 receberam tratamento ambulatorial supervisionado em nosso Centro e 49 delas tiveram seguimento superior a 4 anos (Figura 2).

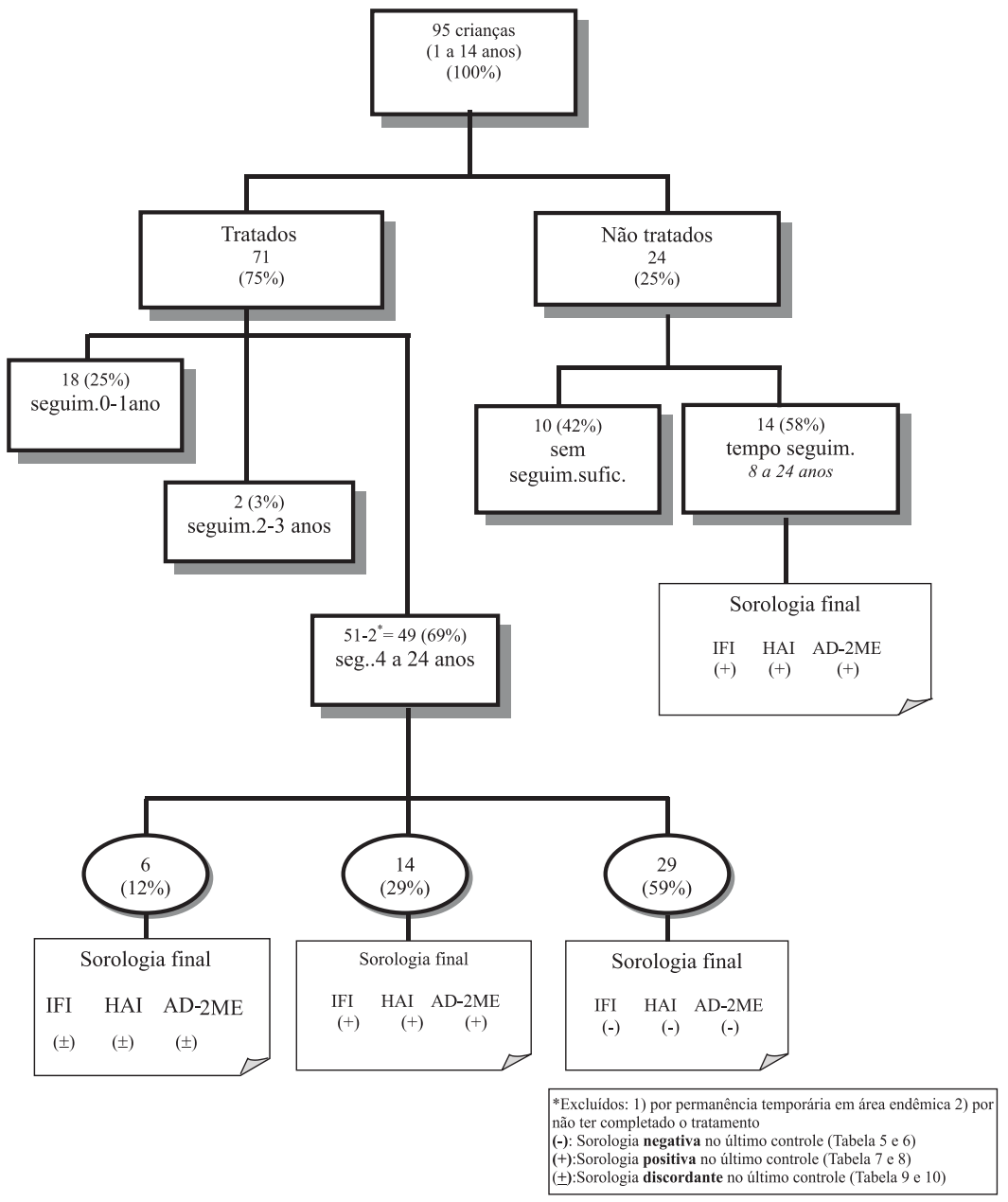

Figura 2 - Esquema do estudo da coortede crianças com infecção chagásica, tratadosenão tratados, residentes em área não endêmica durante o seguimento ( Santa Fé, Argentina, 1976-2002). 
Tolerância ao tratamento. Na Tabela 4, observam-se os efeitos adversos com cada droga. Das 60 crianças que tiveram pelo menos um controle pós-tratamento ( 7 com nifurtimox e 53 com benznidazol) , 2 (3,8\%) apresentaram intolerância ao benznidazol, o que obrigou a suspender a medicação. Nas crianças tratadas com nifurtimox, nenhum caso motivou interrupção do tratamento e os controles seguintes destas crianças foram normais.

Tabela 4- Efeitosadversosem crianças cominfecção chagásica crônica, segundo a droga utilizada para o tratamento (Santa Fé, Argentina, 1976-2002).

\begin{tabular}{ll}
\hline Droga & Efeitos \\
\hline Nifurtimox $(\mathrm{n}=7)$ & anorexia, diminuição de peso, hepatomegalia levemente \\
& dolorosa e transaminase levemente aumentadas, traços \\
& de proteínas e pigmentos biliares na urina
\end{tabular}

Benznidazol $(n=53) \quad$ vômitos, eritema generalizado com edema e prurido

Estudo parasitológico. No início do estudo, foram realizados xenodiagnósticos em 38 crianças. $0 \mathrm{Xd}$ foi positivo em 24 (63\%) crianças, sendo que destas, em 230 xenodiagnóstico era realizado pela primeira vez (Tabelas 5 , 7 e 11) e somente em um recém-nascido com o terceiro Xd (Tabela 9: Caso 2). Das 29 crianças tratadas, 0 xenodiagnóstico prévio foi positivo em 23 (79,3\%). Após 0 tratamento, o xenodiagnóstico negativou em 100\% (23/23) dos casos. Uma menina de 8 anos, com xenodiagnóstico positivo, foi tratada com nifurtimox, e 0 xenodiagnóstico continuou positivo no pós-tratamento. Porém, ao ser tratada com benznidazol, os 8 xenodiagnósticos posteriores foram negativos (Tabela 5 e 6: Caso 21).

Estudo sorológico. Das 49 crianças tratadas (Figura 2) após 4 a 24 anos (mediana de 12 anos) de seguimento póstratamento, $29(59,2 \%)$ negativaram sua sorologia, 14 $(28,6 \%)$ permaneceram positivas (com 2 ou mais reações com titulação de $1 / 32$ ou superior), e $6(12,2 \%)$ apresentaram títulos sorológicos discordantes (Tabela 5 a 10). Nas 24 crianças que não receberam tratamento, 14 tiveram seguimento entre 8 e 24 anos. Todas permaneceram com sorologia positiva (Tabelas 11 e 12).

Na Tabela 13 pode-se observar, por grupos de idade e na Tabela 14 por sexo, a proporção de crianças que negativaram a sorologia. Os resultados sorológicos pós-tratamento segundo 0 sexo não tiveram significação estatística $(p>0,05)$.

A partir dos resultados obtidos pós-tratamento (Tabelas 5 e 7), ainda que a quantidade de crianças tratadas com cada droga seja diferente (e excluindo os casos de resultados com sorologia discordante), observamos na Tabela 15 as percentagens de cura com cada uma delas. Na Figura 4, observa-se que existe correlação linear inversa entre a taxa de negativação sorológica e a idade, estatisticamente significativa, com $r=0,9830\left(r^{2}=0,9664\right)$ e $p=0,017$ (Teste de regressão linear, Stata). A comparação entre as curvas dos dois grupos de idade tratados (long-rang) mostra diferenças estatisticamente significantes entre 5 e $10 \%$

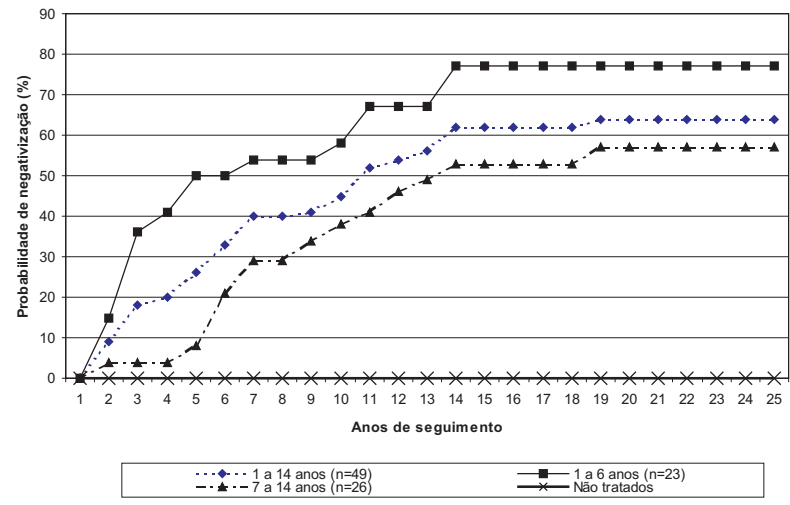

Figura 3 - Probabilidade de negativização sorológica após tratamento tripanocida em crianças na fase crônica assintomatica, segundo grupos de idade ( estimativa Kaplan-Meier).

$(0,10>p>0,05)$. Entre as crianças tratadas e não tratadas, a diferença é altamente significante $(p<0,05)$.

Para calcular a curva de soroconversão de positivos para negativos $\mathrm{S}^{+} \rightarrow S$, utilizamos o método de curvas de vida (Curvas de Kaplan-Meier, teste Long-rank ou Mantel e Hentzel, $\chi^{2}$ ), já que leva em consideração os casos censurados que não compareceram ao controle, e também devido a três fatores: I) pequeno tamanho da amostra; II) as crianças foram tratadas em diferentes idades e III) os controles não se realizaram simultaneamente nem em tempos idênticos. Na Figura 3, observamos a curva de probabilidade de negativação sorológica através do tempo, pós-tratamento, para todos a coorte e as correspondentes a crianças menores e maiores de 6 anos, assim como, a das crianças não tratadas.

As Tabelas 6, 8, 10 e 12 mostram a sorologia através do tempo em crianças tratadas e não tratadas. Consideramos importante observar os resultados sorológicos nos diferentes anos de controle das crianças que negativaram a sorologia final (Tabela 6). Em 20/29 (69\%) a sorologia negativa foi persistente em todos os controles; mas, em 9/29 (31\%) a negatividade/positividade sorológica apresentou-se intermitentemente, sendo ( +) em geral em

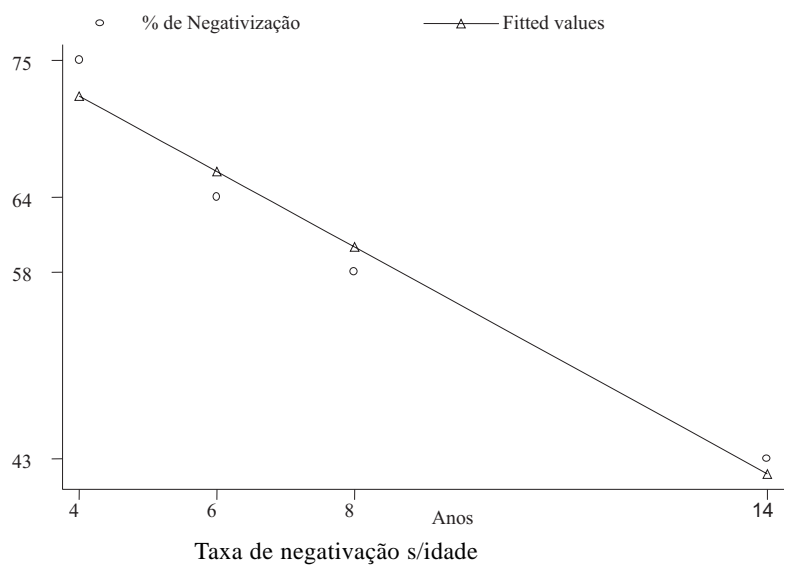

Figura 4 - Teste de regressão linear: Proporção de crianças que negativaram a sorologia para infecção de Chagas crônica após tratamento, de acordo com a idade em anos ( Santa Fé, Argentina, 1976-2002). 
títulos de corte (1/32) em pelo menos dois de três ou quatro reações. Os soros destes 9 pacientes, guardados através do tempo, foram novamente processados simultaneamente e obtiveram-se resultados idênticos.

Nas crianças tratadas em que não desapareceram os anticorpos específicos, na maioria observou-se decrescimento de títulos sorológicos ( Tabelas 8 e 10), enquanto nas não tratadas se mantiveram sem mudanças significativas (Tabelas 12).

Na Tabela 16, se observa 0 tempo de seguimento dos pacientes que negativaram ou não, a sorologia segundo a droga ministrada. Dentre os curados a mediana de seguimento foi maior nos tratados com nifurtimox que com benznidazol, 21 versus 13 anos, enquanto dentre os curados e não curados com esta última (Bz) foi 13 versus 6 anos. É necessário realizar duas considerações: a) o tempo de seguimento total que levaram os pacientes tratados com ambos os medicamentos e b) o tempo em que se apresentou a negativação sorológica com cada droga.
0 tempo total de seguimento dos pacientes tratados com nifurtimox foi maior porque foi a primeira droga utilizada neste estudo. Os tamanhos diferentes dos grupos de crianças tratadas com cada droga e seus diferentes tempos de controle, impedem a nosso critério comparar o tempo de negativação com cada uma. Pode-se especular que mais tempo de seguimento dos pacientes não curado, tratados com benznidazol, poderá resultar em negativação.

\section{DISCUSSÃ0}

Quando iniciamos este estudo de coorte, no final da década de 70, antes de ministrar as drogas tripanossomicida confirmamos a presença de $\mathrm{T}$. cruzi em crianças $\mathrm{S}^{+}$, já que nossa experiência com 0 tratamento específico estava começando e na época a bibliografia sobre estudos longitudinais de pacientes crônicos tratados era escassa ${ }^{9122}$. Quando constatado que os pacientes crônicos com Ac específicos apresentavam algum nível de parasitemia, indicou-se 0 tratamento ainda sem ter realizado

Tabela 5 - Idade, gênero, antecedentes, tratamento e tempo seguimento de crianças com doença de Chagas crônica tratadas que negativaram sorologia, (Santa Fé, Argentina, 1976-2002).

\begin{tabular}{|c|c|c|c|c|c|c|c|c|c|c|c|c|c|c|c|c|c|c|}
\hline \multirow{2}{*}{$\begin{array}{l}\text { Caso } \\
n^{0}\end{array}$} & \multirow{2}{*}{$\begin{array}{r}\text { Idade } \\
\text { (anos) }\end{array}$} & \multicolumn{8}{|c|}{ Antecedentes } & \multicolumn{3}{|c|}{ Sorologia inicial } & \multicolumn{2}{|c|}{ Xenodiagnóstico (n) } & \multicolumn{4}{|c|}{ Sorologia final Pós-Tto } \\
\hline & & $\mathrm{G}$ & migr & S. Mãe & transf & M.Prec** & № filhos & Tto & Anos Seg & IFI & HAI & AD-2ME & Pre-Tto & Pós-Tto & IFI & HAI & $\mathrm{AD}-2 \mathrm{ME}$ & ELISA \\
\hline 1. EM & 1 & $\mathrm{M}$ & $\mathrm{N}$ & + & $\mathrm{N}$ & $\mathrm{N}$ & - & $\mathrm{Bz}$ & 7 & + & + & + & & & - & - & - & \\
\hline 2. RZ & 1a 8m & $\mathrm{F}$ & $\mathrm{N}$ & + & $\mathrm{N}$ & $\mathrm{N}$ & - & $\mathrm{Bz}$ & 11 & + & + & + & & & - & - & 16 & - \\
\hline 3. MM & 2 & M & $\mathrm{N}$ & + & $\mathrm{N}$ & ? & - & $\mathrm{Bz}$ & 7 & + & + & + & $2(+)$ & $5(-)$ & - & 16 & - & \\
\hline 4. EJG & 2a $6 \mathrm{~m}$ & M & $\mathrm{N}$ & + & S & $\mathrm{N}$ & - & $\mathrm{Bz}$ & 12 & + & - & + & & & - & - & 16 & \\
\hline 5. ZR & 3 & $\mathrm{M}$ & $\mathrm{N}$ & + & $\mathrm{N}$ & Ant & - & $\mathrm{Nx}$ & 22 & + & + & + & $1(+)$ & $3(-)$ & - & - & - & \\
\hline 6. $\mathrm{RH}$ & 3a $10 \mathrm{~m}$ & $\mathrm{M}$ & $\mathrm{N}$ & + & $\mathrm{N}$ & $\mathrm{N}$ & - & $\mathrm{Bz}$ & 11 & + & + & + & & & - & - & 16 & - \\
\hline 7. $\mathrm{CA}$ & 4 & $\mathrm{M}$ & $\mathrm{N}$ & + & $\mathrm{N}$ & $\mathrm{N}$ & - & $\mathrm{Nx}$ & 20 & + & - & + & $1(+)$ & $5(-)$ & - & - & - & \\
\hline 8. SCI & 4 & $\mathrm{M}$ & $\mathrm{N}$ & + & $\mathrm{N}$ & $\mathrm{N}$ & - & $\mathrm{Bz}$ & 10 & + & + & + & & & 16 & 16 & 16 & - \\
\hline 9. PC & 4 & F & S & + & $\mathrm{N}$ & Ant & 3 & $\mathrm{NX}$ & 24 & + & - & + & $1(+)$ & $4(-)$ & - & - & - & - \\
\hline 10. PM & 5 & $\mathrm{M}$ & $\mathrm{N}$ & + & $\mathrm{N}$ & $\mathrm{N}$ & - & $\mathrm{Bz}$ & 9 & + & - & + & $1(+)$ & $3(-)$ & - & - & $\cdot$ & \\
\hline 11. IL & 6 & $\mathrm{M}$ & S & - & S & Ant & - & $\mathrm{Bz}$ & 13 & + & + & + & & & - & - & - & - \\
\hline 12. $\mathrm{PB}$ & 6 & F & $\mathrm{N}$ & + & $\mathrm{N}$ & $\mathrm{N}$ & 3 & $\mathrm{NX}$ & 23 & + & - & + & $1(+)$ & $3(-)$ & - & - & - & - \\
\hline 13. SJM & 6 & $\mathrm{M}$ & S & ? & $\mathrm{N}$ & Ant & - & $\mathrm{Bz}$ & 17 & + & + & + & & $2(-)$ & - & - & - & \\
\hline 14. TP & 6 & F & S & + & $\mathrm{N}$ & $\mathrm{N}$ & - & $\mathrm{Bz}$ & 13 & + & + & + & $1(+)$ & $2(-)$ & - & - & - & \\
\hline 15. BMI & 6 & $\mathrm{~F}$ & $\mathrm{~N}$ & + & $\mathrm{N}$ & At & - & $\mathrm{Bz}$ & 14 & + & + & + & $1(+)$ & $4(-)$ & 16 & - & - & - \\
\hline 16. VC & 6 & $\mathrm{~F}$ & S & - & $\mathrm{N}$ & Ant & 2 & $\mathrm{Bz}$ & 15 & + & + & + & & & - & - & - & . \\
\hline 17. GL & 7 & $\mathrm{~F}$ & S & + & $S$ & At & 2 & $\mathrm{Bz}$ & 12 & + & + & + & & & - & - & $\cdot$ & \\
\hline 18. CM & 7 & $\mathrm{~F}$ & S & - & $\mathrm{N}$ & At & - & $\mathrm{Bz}$ & 8 & + & + & + & & & - & - & 16 & \\
\hline 19. RO & 7 & $\mathrm{M}$ & $\mathrm{N}$ & + & $\mathrm{N}$ & $\mathrm{N}$ & - & $\mathrm{Bz}$ & 18 & + & + & + & $1(+)$ & $2(-)$ & - & - & 16 & - \\
\hline 20. TM & 7 & F & $\mathrm{N}$ & + & $?$ & $\mathrm{~N}$ & - & $\mathrm{Bz}$ & 18 & + & + & + & $1(+)$ & $3(-)$ & - & - & 16 & - \\
\hline 21.GMJ\# & 8 & F & S & ? & ? & Ant & & $\mathrm{Nx}-\mathrm{Bz}$ & 21 & t & t & + & $2(+)$ & $8(-)$ & - & - & - & - \\
\hline 22. MC & 8 & $\mathrm{~F}$ & S & ? & $\mathrm{N}$ & Ant & 1 & $\mathrm{Bz}$ & 17 & + & + & + & $1(+)$ & $2(-)$ & 16 & 16 & 16 & - \\
\hline 23. VH & 8 & $\mathrm{M}$ & $\mathrm{N}$ & + & $\mathrm{N}$ & $\mathrm{N}$ & - & $\mathrm{Bz}$ & 13 & + & - & + & & & - & - & 16 & \\
\hline 24. DS & 9 & F & $\mathrm{N}$ & + & $?$ & $\mathrm{~N}$ & 1 & $\mathrm{Bz}$ & 21 & + & + & + & $1(+)$ & $8(-)$ & - & 16 & 16 & - \\
\hline 25. BT & 10 & $\mathrm{M}$ & S & + & $\mathrm{N}$ & Ant & - & $\mathrm{Nx}$ & 15 & + & + & + & $1(+)$ & $5(-)$ & - & - & - & \\
\hline 26. FN & 11 & F & $S$ & + & $S$ & At & 1 & $\mathrm{Bz}$ & 12 & + & + & + & & $3(-)$ & - & - & - & \\
\hline 27. OM & 13 & $\mathrm{M}$ & S & - & $\mathrm{N}$ & $\mathrm{N}$ & - & $\mathrm{Bz}$ & 18 & + & + & + & $1(+)$ & $3(-)$ & - & - & 16 & - \\
\hline 28. AM & 14 & F & S & + & $\mathrm{N}$ & Ant & 5 & $\mathrm{Bz}$ & 11 & + & + & + & & & - & - & - & - \\
\hline $29 \mathrm{BN}$ & 14 & $\mathrm{~F}$ & S & + & $\mathrm{N}$ & Ant & 1 & $\mathrm{Nx}$ & 15 & + & + & + & $1(+)$ & $1(-)$ & - & - & - & \\
\hline
\end{tabular}

G: gênero. M: masculino. F: feminino. Tto: tratamento. Bz: benznidazol. Nx: nifurtimox. Xd (n): Quantidade de Xd realizados (Pré e Pós Tto). (+): positivo. (-): negativo. *IFI: inmunofluorescência indireta. *HAI: hemoaglutinação indireta. *AD-2ME: aglutinação direta com 2 mercaptoetanol.

* Consideram-se positivos títulos $\geq 32$. ( +): positivo. (-) : negativo. ( \pm ) : duvidoso. Migr: migrações área endêmica. S.Mãe: sorologia materna. Transf: transfusões. M. Prec**: moradia precária no momento do Tto. Ant: anterior. At: atual. № filhos de mulheres: Quantidade de filhos no último controle só das mulheres. \# Ao se observar falha terapêutica com nifurtimox por um xenodiagnóstico positivo, se tratou pela $2^{\mathrm{a}}$ vez com benznidazol, com oito xenodiagnósticos posteriores negativos. 
0 xenodiagnóstico prévio ou se 0 mesmo tivesse dado negativo ${ }^{511} 12$. Este fato explica o porquê a seleção dos grupos não foi feita aleatoriamente.

Os dados das crianças infectadas que negativaram sua sorologia após tratamento antiparasitário específico, com seguimento de até 24 anos, confirmam (ainda que em percentagem levemente menor) os resultados obtidos por nosso grupo de trabalho no ano 1993 e confirmam que a probabilidade de cura é maior quanto menor é a idade do paciente tratado. Levando em consideração que as crianças não foram controladas com a mesma freqüência nem em lapsos iguais (a distribuição não é gaussiana), a melhor medida de tendência central para fazer a estimativa do tempo em que desapareceram os anticorpos anti-T.cruzi, após finalizado 0 tratamento, é a mediana. Para as crianças tratadas entre 1 e 6 anos, a mediana foi de 3 anos e 6 meses, y nos que receberam tratamento entre os 7 e 14 anos foi de 8 anos.

Com relação à negativação da sorologia, se observaram algumas variações ao longo do seguimento pós-tratamento. A reatividade dos soros que apresentaram intermitência negatividade/positividade foi em títulos próximos aos de corte (1/32) na população estudada. Estes resultados, corroborados ao processar simultaneamente os soros estocados, permitiram descartar que a variação pudesse ser devido à remessa de antígenos utilizada nos diferentes controles. Se bem que os erros dos métodos sorológicos, por ação do técnico, são até de duas diluições ${ }^{20}$, a positividade nos títulos limites se apresentou em pelo menos duas das reações realizadas. Estas oscilações também poderiam ser atribuídas a certo grau de inespecificidade dos métodos sorológicos convencionais que utilizam Ag total de T. cruzi ${ }^{28}$. Porém, deve se destacar que nas crianças não tratadas, a sorologia se manteve persistentemente positiva e não se apresentaram grandes flutuações na titulação. Enquanto não seja possível a aplicação imediata de técnicas diretas, baseadas em metodologias de biologia molecular, com comprovada sensibilidade e especificidade, se deve levar em consideração a apresentação destas intermitências (memória imunológica, presença de frações antigênicas?) , ainda que tenham se observado em menos de um terço das crianças que negativaram a sorologia.

Resulta difícil comparar os resultados com outros trabalhos de avaliação terapêutica de crianças, por diferenças de tempo, lugar e pessoa, assim como, por diferentes desenhos, duração e doses de drogas ministradas, assim como a metodologia de avaliação ${ }^{3} 13141828$. Alguns foram ensaios clínicos randomizados, 0 tempo de administração do benznidazol foi de 60 dias e para 0

Tabela 6 - Crianças com doença de Chagas crônica tratadas que negativaram sorologia, e nos anos de controle, (Santa Fé, Argentina, 1976-2002).

\begin{tabular}{|c|c|c|c|c|c|c|c|c|c|c|c|c|c|c|c|c|c|c|c|c|c|c|c|c|c|c|}
\hline $\begin{array}{l}\text { Caso } \\
n^{\circ}\end{array}$ & $\begin{array}{l}\text { Idade } \\
\text { (anos) }\end{array}$ & $\begin{array}{c}\text { Tempo } \\
\text { controle (anos) }\end{array}$ & 0 & 1 & 2 & 3 & 4 & 5 & 6 & 7 & 8 & 9 & 10 & 11 & 12 & 13 & 14 & 1516 & 17 & 18 & 19 & 20 & 21 & 22 & 23 & 24 \\
\hline 1. EM & 1 & 7 & + & + & - & & - & - & & - & & & & & & & & & & & & & & & & \\
\hline 2. RZ & 1a $8 \mathrm{~m}$ & 11 & + & - & & - & & - & - & & - & & & - & & & & & & & & & & & & \\
\hline 3. MM & 2 & 7 & + & - & - & - & - & - & & - & & & & & & & & & & & & & & & & \\
\hline 4. EJG & $2 \mathrm{a} 6 \mathrm{~m}$ & 12 & + & & - & & & - & - & - & & - & & & - & & & & & & & & & & & \\
\hline 5. ZR & 3 & 22 & + & + & + & + & + & & & & & & - & & - & & & - & - & & & - & & - & & \\
\hline 6. RH & 3a 10m & 11 & + & + & - & - & & + & - & & + & & & - & & & & & & & & & & & & \\
\hline 7. CA & 4 & 20 & + & & + & + & & & & & & - & + & & + & & & - & - & & & - & & & & \\
\hline 8. SCI & 4 & 10 & + & + & & + & & & - & & - & & - & & & & & & & & & & & & & \\
\hline 9. PC & 4 & 24 & + & + & & & - & & & & + & & & - & & + & - & - & - & & + & & & - & & - \\
\hline 10. PM & 5 & 9 & + & - & - & & + & & - & - & & - & & & & & & & & & & & & & & \\
\hline 11. IL & 6 & 13 & + & + & & & & & & & & & & & & - & & & & & & & & & & \\
\hline 12. PB & 6 & 23 & + & & & & & + & + & + & & & & + & & - & - & - & & & & & & & - & \\
\hline 13. SJM & 6 & 17 & + & + & & - & & & & & & & & & & & & - & - & & & & & & & \\
\hline 14. TP & 6 & 13 & + & + & + & + & - & & + & + & - & & & - & & - & & & & & & & & & & \\
\hline 15. BMI & 6 & 14 & + & + & - & - & - & & & & & & & - & & & - & & & & & & & & & \\
\hline 16. VC & 6 & 15 & + & & & & & & & & & & - & & & & & - & & & & & & & & \\
\hline 17. GL & 7 & 12 & + & - & - & - & & - & & & & - & & & - & & & & & & & & & & & \\
\hline 18. CM & 7 & 8 & + & & & & & & & & - & & & & & & & & & & & & & & & \\
\hline 19. R0 & 7 & 18 & + & + & + & + & - & + & - & + & & - & + & & & + & - & - & & - & & & & & & \\
\hline 20. TM & 7 & 18 & + & + & + & + & & & & & & - & - & & & & - & - & & & & & & & & \\
\hline 21.GMJ & 8 & 21 & + & & + & + & + & - & & + & & & & + & & - & + & & & & & & - & & & \\
\hline 22. MC & 8 & 17 & + & + & & & + & + & + & & + & & - & & + & & & - & - & & & & & & & \\
\hline 23. VH & 8 & 13 & + & & & & & & & & & & & & & - & & & & & & & & & & \\
\hline 24. DS & 9 & 21 & + & + & & & + & + & - & + & & + & & & - & & - & & & - & & & - & & & \\
\hline 25. BT & 10 & 15 & + & + & & + & & - & - & & & & - & & & & & - & & & & & & & & \\
\hline 26. FN & 11 & 12 & + & + & + & + & & & + & & & & & & - & & & & & & & & & & & \\
\hline 27. OM & 13 & 18 & + & + & & & + & & & & + & & + & & + & + & & & & - & & & & & & \\
\hline 28. AM & 14 & 11 & + & + & & + & & & & & & & & - & & & & & & & & & & & & \\
\hline 29. BN & 14 & 15 & + & + & & & & - & & & & & & & - & & & - & & & & & & & & \\
\hline
\end{tabular}

Tpo.: tempo, 0: Controle inicial pré tratamento, 1, 2, 3, 4....: Anos, controle pós-tratamento, Sorologia (+): positivo $\geq 32$. (-): negativo mediana do tempo de negativação - crianças 1 a 6 anos de idade: 3,5 anos, crianças 7 a 14 anos de idade: 8 anos 
critério de cura se realizaram outras técnicas sorológicas não convencionais. Estas experiências na Argentina ${ }^{13}{ }^{18}$ e no Brasil $^{3}{ }^{28}$, utilizaram frações antigênicas ( F29, f2/3) para avaliar a eficácia e se observaram, em menor tempo de seguimento pós-tratamento, porcentagens de negativação similares ao deste trabalho. Ao utilizar como Ag frações do parasito, aumenta a especificidade da reação sorológica, mas, diminui a sensibilidade. Estes novos métodos podem ser ferramentas importantes como marcadores iniciais da eficácia da terapêutica. Porém, 0 critério de cura ainda segue sendo a ausência de anticorpos anti-T.cruzi na sorologia convencional, já que é válida para o diagnóstico e é 0 que ainda se utiliza, ainda, na rotina nos serviços de saúde, apesar da limitação que pode apresentar8 $28{ }^{42}$. Cabe destacar que com os métodos sorológicos convencionais podem se comparar pesquisas realizada em diferentes lugares, além de serem práticos e de fácil realização em laboratórios de menor complexidade.

Os métodos parasitológicos tradicionais ${ }^{127} 39$ ou os mais modernos como biologia molecular ${ }^{60}$ apresentam dificuldade operacional, de sensibilidade, acessibilidade e/ou transferência tecnológica. Porem, servem como métodos auxiliares em trabalhos de pesquisa, indicando o perfil parasitológico do paciente, 0 efeito supressivo dos fármacos empregados e, quando positivos no período pós-tratamento induvidável falha terapêutica ${ }^{728}$. A via pela qual as crianças adquiriram a infecção poderia ter influência na negativação sorológica após tratamento etiológico, mas, nos poucos casos com somente um antecedente epidemiológico de provável porta de entrada do T. cruzi não se observou associação entre alguma delas e a evolução clínica ou sorológica. Seria

Tabela 7 - Idade, gênero, antecedentes, e tempo seguimento crianças com doença de Chagas crônica tratadas que não negativaram sorologia ( Santa Fé, Argentina, 1976-2002).

\begin{tabular}{|c|c|c|c|c|c|c|c|c|c|c|c|c|c|c|c|c|c|c|}
\hline \multirow{2}{*}{$\begin{array}{l}\text { Caso } \\
n^{0}\end{array}$} & \multirow{2}{*}{$\begin{array}{l}\text { Idade } \\
\text { (anos) }\end{array}$} & \multirow[b]{2}{*}{ G } & \multicolumn{6}{|c|}{ Antecedentes } & \multirow[b]{2}{*}{ Anos Seg } & \multicolumn{5}{|c|}{ Sorologia inicialXenodiagnóstico (n) } & \multicolumn{4}{|c|}{ Sorologia final Pós-Tto } \\
\hline & & & Migr & S.Mãe & Transf & M.Prec** & № filhos & Tto & & IFI & $\mathrm{HAI}$ & $\overline{\mathrm{AD}-2 \mathrm{ME}}$ & Pre-Tto & Pós-Tto & $\overline{\mathrm{IFI}}$ & $\mathrm{HAI}$ & AD-2ME & ELISA \\
\hline 1. AA & 3 & $\mathrm{~F}$ & $\mathrm{~N}$ & + & $\mathrm{N}$ & Ant & - & $\mathrm{Bz}$ & 6 & + & + & + & $1(+)$ & & 32 & 32 & 32 & + \\
\hline 2. PL & 4 & $\mathrm{~F}$ & $\mathrm{~N}$ & $t$ & $\mathrm{~N}$ & $\mathrm{~N}$ & - & $\mathrm{Bz}$ & 6 & + & + & $t$ & & & 32 & 32 & 32 & - \\
\hline 3. VF & 4 & $\mathrm{~F}$ & S & + & $\mathrm{N}$ & Ant & - & $\mathrm{Bz}$ & 7 & + & + & + & & & 32 & 32 & 32 & + \\
\hline 4. BLM & 6 & $\mathrm{M}$ & $\mathrm{N}$ & $t$ & $\mathrm{~N}$ & At & - & $\mathrm{Bz}$ & 5 & + & + & $t$ & $1(-)$ & & 32 & 32 & 32 & \\
\hline 5. RG & 6 & M & S & $t$ & $\mathrm{~N}$ & Ant & - & $\mathrm{Bz}$ & 4 & + & + & $t$ & $1(+)$ & & + & 32 & 32 & \\
\hline 6. SC & 6 & $\mathrm{M}$ & S & + & $\mathrm{N}$ & Ant & - & $\mathrm{Bz}$ & 6 & + & + & + & & & 64 & $>64$ & 32 & \pm \\
\hline 7. VP & 6 & M & S & + & $\mathrm{N}$ & Ant & - & $\mathrm{Bz}$ & 7 & + & + & + & & & 32 & 32 & 32 & + \\
\hline 8. GC & 7 & $\mathrm{~F}$ & S & - & $\mathrm{N}$ & At & - & $\mathrm{Bz}$ & 6 & + & + & $t$ & & & + & 64 & 64 & \\
\hline 9. $\mathrm{AA}^{\prime}$ & 8 & $\mathrm{~F}$ & $\mathrm{~N}$ & + & S & Ant & - & $\mathrm{Bz}$ & 15 & + & + & + & $1(-)$ & & + & $>32$ & $>64$ & \\
\hline 10. GR & 11 & $\mathrm{M}$ & $\mathrm{N}$ & $t$ & $\mathrm{~N}$ & $\mathrm{~N}$ & - & $\mathrm{Bz}$ & 5 & + & + & + & & & 64 & 32 & 64 & \\
\hline 11. SCR & 12 & $\mathrm{M}$ & $\mathrm{N}$ & $t$ & $\mathrm{~N}$ & $\mathrm{~N}$ & - & $\mathrm{Bz}$ & 10 & + & + & + & & & 32 & 64 & 32 & + \\
\hline 12. RT & 13 & $\mathrm{~F}$ & S & + & $\mathrm{N}$ & Ant & 3 & $\mathrm{Bz}$ & 21 & + & + & + & $1(+)$ & $2(-)$ & 64 & $>64$ & 128 & \\
\hline 13. VD & 13 & $\mathrm{~F}$ & S & + & $\mathrm{N}$ & Ant & - & $\mathrm{Bz}$ & 4 & + & + & + & & & 64 & 32 & 32 & \\
\hline 14. VA & 14 & F & S & + & $\mathrm{N}$ & Ant & - & $\mathrm{Bz}$ & 7 & + & + & + & & & 32 & 64 & 64 & + \\
\hline
\end{tabular}

G: gênero. M: masculino. F: feminino N: Năo S: Sim. Tto: tratamento. Bz: benznidazol. Xd (n): Quantidade de Xd realizados ( Pré e Pós Tto). (+): positivo. (-): negativo.

*IFI: inmunofluorescência indireta. *HAI: hemoaglutinação indireta. *AD-2ME: aglutinação direta com 2 mercaptoetanol. $\quad *$ Consideram-se positivos títulos e $\geq 32$. ( + ): positivo. (-): negativo. ( \pm ): duvidoso. Migr: migrações área endêmica. S.Mãe: sorologia materna. Transf: transfusões. M.Prec**: moradia precária no momento do Tto. Ant: anterior. At: actual. № filhos de mulheres: Quantidade de filhos no último controle só das mulheres. Grupo de idade: 3 a 14 anos. Idade mediana: 6,5 anos.Tempo de seguimento: 4 a 21 anos Mediana: 6 anos

Tabela 8 - Crianças com doença de Chagas crônica tratadas que não negativaram sorologia, nos anos de controle (por razões de espaço se consignam títulos até os 10 anos de seguimento) (Santa Fé, Argentina, 1976-2002).

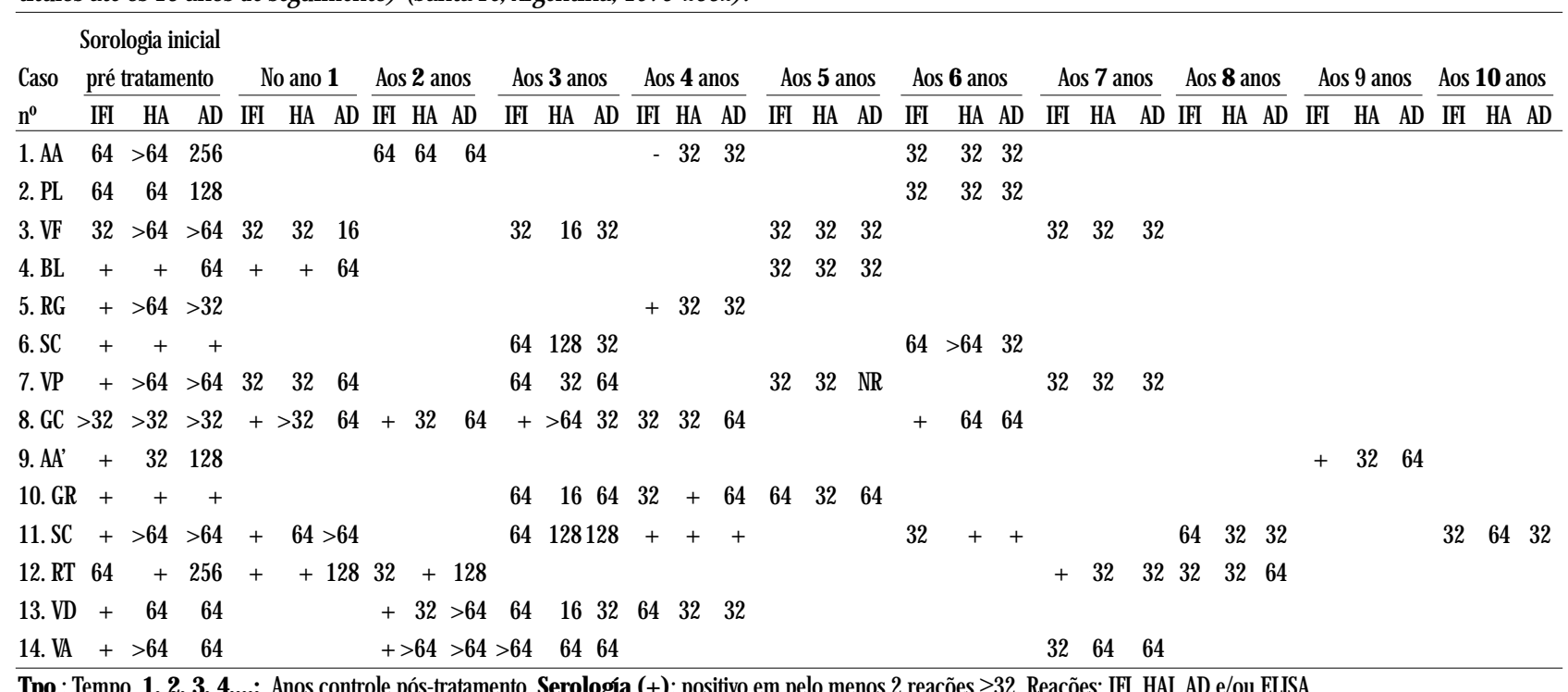


interessante realizar estudos de caracterização das cepas de T. cruzi na infecção da população, dado que se conhece a existência de cepas resistentes às drogas disponíveis atualmente ${ }^{232}$.

Pela díspar quantidade de crianças tratadas com cada fármaco, não se pode comparar estatisticamente para avaliar a intolerância nem qual droga apresenta melhor efeito. Nas crianças tratadas com nifurtimox se apresentaram dois com falha terapêutica e nos tratados com benznidazol dois casos de intolerância.

Neste estudo, não se tem observado 0 aparecimento de anormalidades da doença de Chagas, por ECG e exames clínicos, durante 0 seguimento prolongado (mediana 13 anos de seguimento), tanto em crianças tratadas como nas que não foram tratadas. Outros autores acharam alterações no início ou ao finalizar os controles, aos 4 anos. É necessário neste estudo, em que crianças moram desde pequenas em áreas não endêmicas e portanto não estão expostos à reinfecções, realizar seguimento clínico por mais tempo nos grupos tratados e não tratados, já que provavelmente não apareceram alterações ainda devido a sua curta idade, onde há predomínio das formas crônicas assintomáticas ${ }^{73} 3342$.

Tabela 9 - Idade, gênero, antecedentes, tratamento e tempo seguimento crianças com doença de Chagas crônica tratadas com sorologia final discordante (Santa Fé, Argentina, 1976-2002).

\begin{tabular}{|c|c|c|c|c|c|c|c|c|c|c|c|c|c|c|c|c|c|c|}
\hline \multirow{2}{*}{$\begin{array}{l}\text { Caso } \\
n^{0}\end{array}$} & \multirow{2}{*}{$\begin{array}{l}\text { Idade } \\
\text { (anos) }\end{array}$} & \multirow[b]{2}{*}{ G } & \multicolumn{5}{|c|}{ Antecedentes } & \multirow[b]{2}{*}{ Tto } & \multirow[b]{2}{*}{ Anos Seg } & \multicolumn{3}{|c|}{ Sorologia inicial } & \multicolumn{3}{|c|}{ Xenodiagnóstico (n) } & \multicolumn{3}{|c|}{ Sorologia final Pós-Tto } \\
\hline & & & Migr & S. Mãe & Transf & M. Prec** & № filhos & & & IFI & HAI & AD-2ME & Pre-Tto & Pós-Tto & IFI & HAI & $\mathrm{AD}-2 \mathrm{ME}$ & ELISA \\
\hline 1. AS & 7 & $\mathrm{~F}$ & $S$ & + & $\mathrm{N}$ & Ant & 6 & $\mathrm{Bz}$ & 15 & + & + & + & & & + & - & 16 & \pm \\
\hline 2. $\mathrm{AE}$ & 7 & M & S & $?$ & $\mathrm{~N}$ & At & - & $\mathrm{Bz}$ & 9 & + & + & + & $2(-) 1(+)$ & $3(-)$ & 32 & - & 16 & \\
\hline 3. LV & 8 & $\mathrm{~F}$ & $\mathrm{~N}$ & + & S & Ant & 2 & $\mathrm{Bz}$ & 16 & + & + & + & $1(+)$ & $2(-)$ & 16 & 16 & 16 & + \\
\hline 4. $\mathrm{BD}$ & 9 & $\mathrm{~F}$ & S & + & S & Ant & - & $\mathrm{Bz}$ & 9 & + & + & + & & & + & - & 32 & - \\
\hline 5. SW & 9 & M & S & + & $\mathrm{N}$ & Ant & - & $\mathrm{Bz}$ & 8 & + & + & + & & & 16 & $32 d$ & 32 & \\
\hline 6. SP & 10 & $\mathrm{M}$ & S & + & $\mathrm{N}$ & Ant & - & $\mathrm{Bz}$ & 7 & + & + & + & & & 16 & $32 d$ & 32 & \\
\hline
\end{tabular}

G: gênero. M: masculino. F: feminino. Tto: tratamento. Bz: benznidazol. Xd (n): Quantidade de Xd realizados (Pré y Pós Tto) . (+): positivo. (-): negativo. *IFI: inmunofluorescência indireta. *HAI: hemoaglutinação indireta. *AD-2ME: aglutinação direta com 2 mercaptoetanol. * Consideram-se positivos títulos $\geq 32$. ( +): positivo. (-): negativo. ( \pm ): duvidoso. d: débil. Migr: migrações área endêmica. S.Mãe: sorologia materna. Transf: transfusões. M.Prec**: moradia precária no momento do Tto. Ant: anterior. At: atual. № filhos de mulheres: Quantidade de filhos no último controle só das mulheres. Grupo de idade: 7 a 10 anos. Idade Mediana: 8,5 anos. Tempo de seguimento: 7 a 16 anos. Mediana: 9 anos. $\mathbf{S}=\operatorname{sim}, \mathbf{N}=$ não.

Tabela 10 - Crianças com doença de Chagas crônica tratadas com sorologia final discordante, nos anos de controle ( Santa Fé, Argentina, 1976-2002).

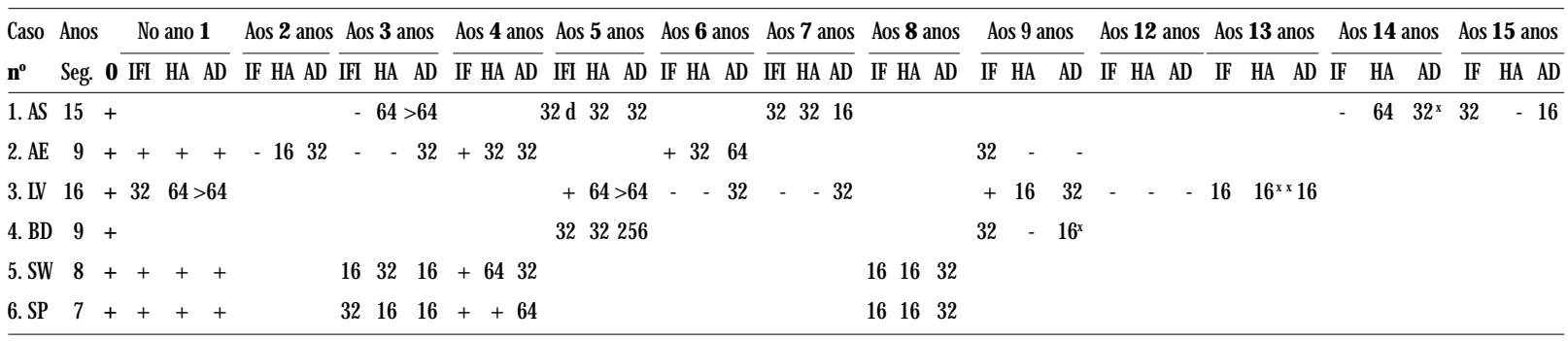

0: Controle inicial pré tratamento, 1, 2, 3, 4....: Anos controle pós-tratamento, Sorologia (+): positivo. ( \pm ): discordante.Reações: IFI, HAI, AD e/ou ELUSA

xELSA: negativo. ${ }^{\mathrm{xx}}$ ELSA: positivo

Tabela 11 - Idade, gênero, antecedentes, tratamento e tempo seguimento de crianças com doença de Chagas crônica - não tratadas ( Santa Fé, Argentina, 1976-2002).

\begin{tabular}{|c|c|c|c|c|c|c|c|c|c|c|c|c|c|c|c|}
\hline \multirow{2}{*}{$\begin{array}{l}\text { Caso } \\
n^{\circ}\end{array}$} & \multirow{2}{*}{$\begin{array}{l}\text { Idade } \\
\text { (anos) }\end{array}$} & \multirow[b]{2}{*}{ G } & \multicolumn{5}{|c|}{ AntecedentesAnos } & \multirow[b]{2}{*}{ Anos seg } & \multicolumn{3}{|c|}{ Sorologia inicial } & \multirow[b]{2}{*}{ Xd nol início (n) } & \multicolumn{3}{|c|}{ Seguimento sorológico ( final) } \\
\hline & & & Migr & S. Mãe & Transf & M. Prec** & № filhos & & IFI & HAI & $\mathrm{AD}-2 \mathrm{ME}$ & & IFI & HAI & $\mathrm{AD}-2 \mathrm{ME}$ \\
\hline $1 . \mathrm{OR}$ & 4 & $\mathrm{M}$ & $?$ & + & $\mathrm{N}$ & $?$ & - & 11 & + & + & + & & + & 64 & $>64$ \\
\hline 2. OW & 6 & M & $\mathrm{N}$ & + & $\mathrm{N}$ & $\mathrm{N}$ & - & 18 & + & & + & $1(-)$ & 32 & $>64$ & 64 \\
\hline 3. MC & 8 & $\mathrm{~F}$ & S & $?$ & $\mathrm{~N}$ & $\mathrm{~N}$ & - & 20 & + & + & + & $1(-)$ & 128 & 64 & 64 \\
\hline 4. PE & 9 & M & S & $?$ & $\mathrm{~N}$ & Ant & - & 9 & + & + & + & $1(-)$ & + & $>64$ & $>64$ \\
\hline 5. BR & 10 & $\mathrm{~F}$ & S & + & $\mathrm{N}$ & Ant & 1 & 14 & + & + & + & $5(-)$ & + & 32 & 32 \\
\hline 6. SB & 11 & $\mathrm{~F}$ & S & $?$ & $\mathrm{~N}$ & At & 1 & 12 & + & + & + & & 64 & 64 & $>64$ \\
\hline 7. AS & 13 & M & $\mathrm{N}$ & + & $\mathrm{N}$ & At & - & 13 & + & + & + & & $>128$ & $>64$ & 64 \\
\hline 8. $A B$ & 14 & F & S & $?$ & $\mathrm{~N}$ & Ant & - & 8 & + & + & + & & 64 & 64 & $>64$ \\
\hline 9. AO & 14 & M & S & ? & $\mathrm{N}$ & Ant & - & 17 & + & + & + & $1(-)$ & 64 & 64 & 32 \\
\hline 10. GA & 14 & F & S & + & $\mathrm{N}$ & Ant & 5 & 16 & + & + & + & & 64 & 16 & 32 \\
\hline 11. IL & 14 & $\mathrm{~F}$ & S & + & $\mathrm{N}$ & Ant & - & 24 & + & + & + & $1(-)$ & $>128$ & $>64$ & $>64$ \\
\hline 12. IA & 14 & M & S & $?$ & $\mathrm{~N}$ & $\mathrm{~N}$ & - & 15 & + & + & + & & 64 & 64 & 64 \\
\hline 13. RS & 14 & F & $\mathrm{N}$ & + & $\mathrm{S}$ & Ant. & 5 & 23 & + & + & + & $1(+)(E m b)$ & 128 & $>64$ & $>64$ \\
\hline 14. RE & 14 & F & $\mathrm{S}$ & + & $\mathrm{N}$ & At. & 4 & 16 & + & + & + & $1(-)$ & + & $>64$ & 32 \\
\hline
\end{tabular}

G: gênero. M: masculino. F: feminino. Xd (n): Quantidade de Xd realizados. (+): positivo. (-): negativo. *IFI: inmunofluorescência indireta. *HAI: hemoaglutinação indireta. *AD-2ME: aglutinação direta com 2 mercaptoetanol . *Consideram-se positivos títulos $\geq 32$. (+): positivo. (-): negativo. ( \pm ): duvidoso. Migr: migrações área endêmica. S.Mãe: sorologia materna. Transf: transfusões. M.Prec**: moradia precária no momento do Tto. Ant: anterior.. Act: atual.

№ filhos de mulheres: Quantidade de filhos no último controle só das mulheres. Grupo de idade: 4 a 14 anos. Idade mediana: 13,5 anos. Tempo de seguimento: 8 a 24 anos. Mediana: 15,5 anos. $\mathbf{S}=\operatorname{sim}, \mathbf{N}=$ não. 
As crianças que apresentaram algum retardo neurológico tinham como único antecedente epidemiológico mães soropositivas. Năo podemos inferir que 0 atraso na maturidade seja devido exclusivamente à doença de Chagas e/ou à via de infecção, já que estas famílias por sua condição socioeconômica estão expostas a múltiplos fatores que podem causar estes danos.

Nos três grupos de crianças com diferentes resultados sorológicos finais, tendo recebido todos eles tratamento tripanossomicida, a diferença mais notória que se observa em cada um é a mediana do tempo de seguimento pós-tratamento: enquanto nos que negativaram sua sorologia foi de 14 anos, nos discordantes a mediana do tempo de seguimento foi 9 anos, e nos que permaneceram positivos foi de 6 anos. Os dados sugeriam que se deve dar um tempo para que se produza a negativação, como também fora indicado por Luquetti \& Rassi ${ }^{28}$. Segundo uma cinética ainda não bem conhecida, alguns casos com sorologia discordante e/ou positiva, poderão eventualmente negativar nos próximos ano ${ }^{828}$. Nas crianças que foram tratadas, a percentagem de conversão a soronegativos diminuiu com a idade em que se administrou a medicação tripanossomicida, desde $75 \%$ em $\leq 4$ anos até $43 \% \mathrm{em} \geq 9$ anos. Estes resultados indicam a importância do diagnóstico e tratamento precoce já que o beneficio é maior quanto menor a idade, como foi sugerido também em outras pesquisas ${ }^{31826}$.

Na luz desta e outras experiências 123813182630 , pode-se concluir que 0 tratamento específico disponível, ainda que distante do ideal, confere benefícios concretos para as pessoas de pouca idade infectadas pelo T. cruzi. Além de seguir procurando novas e melhores drogas para este tratamento, é também necessário contar com ferramentas sensíveis e específicas que possam ser transferidas rapidamente aos serviços de saúde, para monitorar 0 tratamento específico de forma segura e eficiente.

Tabela 12 - Seguimento através de sorologia em crianças com doença de Chagas crônica, não tratadas, nos anos de controle (Santa Fé, Argentina, 19762002).

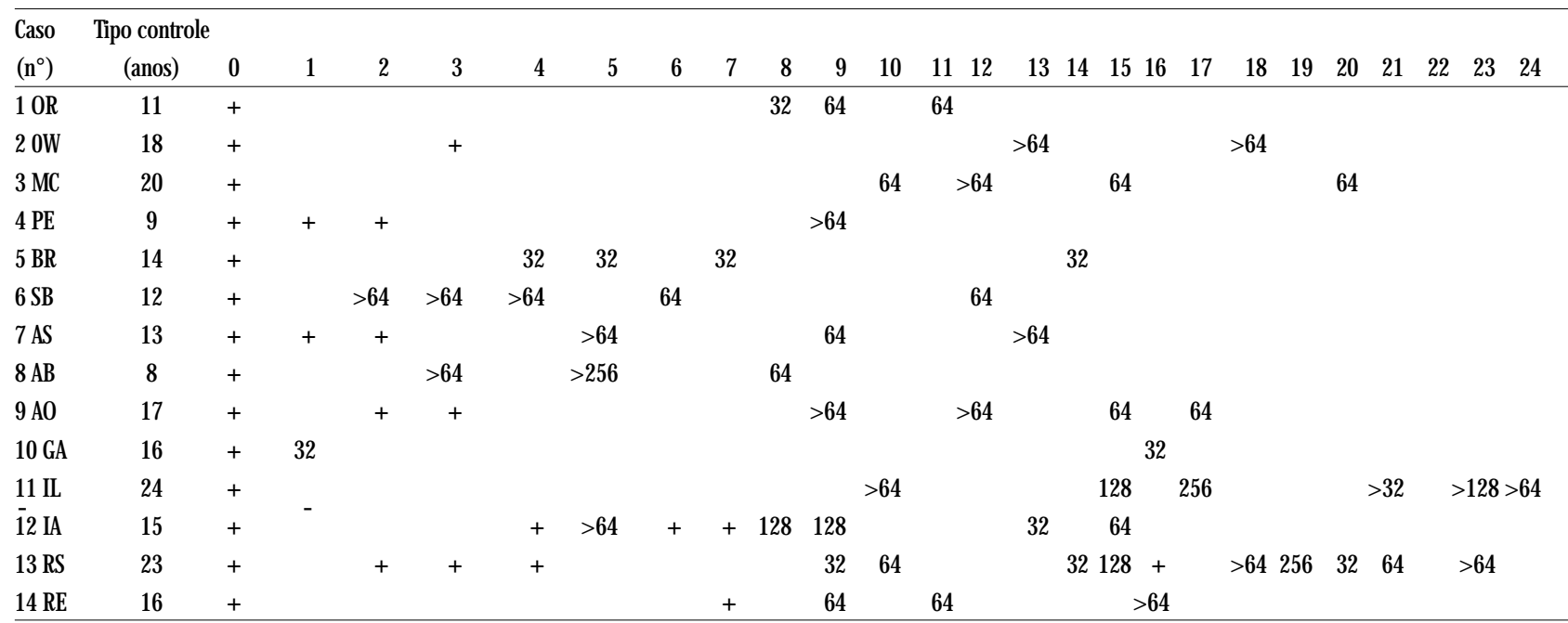

Tpo:: Tempo, 0: Controle inicial, 1, 2, 3, 4....: Anos de controle, (+): sorologia positiva, pelo menos 2 reações $\geq 32 . \rightarrow{ }^{*}$ Reações: IFl, HAI, AD e/ou ELISA $\rightarrow$ Títulos informados correspondem a HAI.

Tabela13- Proponçãodecriancascominfecção chagásica crônica quenegativaram a sorologia convencional, durante o seguimento e $>4$ anos pós tratamento tripanossomicida, por grupos deidade( Santa Fé, Argentina, 1976-2002).

\begin{tabular}{lcrr}
\hline Idade (anos) & Total de crianças & \multicolumn{2}{c}{ Sorologianegativa } \\
\cline { 3 - 4 } & $\mathrm{n}^{0}$ & $\mathrm{n}^{0}$ & $\%$ \\
\hline 1 a 4 & 12 & 7 & 75,0 \\
5 a 6 & 11 & 7 & 54,0 \\
7 a 8 & 12 & 6 & 43,0 \\
9 a 14 & 14 & 29 & 59,0 \\
\hline Total & 49 & &
\end{tabular}

$\chi^{2}(p>0,05), r^{2}=0,9664 \quad r=-0,9830 \quad p=0,017$

Tabela 15 - Resultados do tratamento em crianças com doença de Chagas crônico para cada uma das drogas administradas, e das crianças não tratadas (Santa Fé, Argentina, 1976-2002).

\begin{tabular}{lccccr}
\hline & Droga & Curados* & Nâo curados* & Total & Cura (\%) \\
\hline Tratados & benznidazol & 23 & 14 & 37 & 62,2 \\
& nifurtimox & 6 & 1 & 7 & 85,7 \\
& total & 29 & 15 & 44 & 65,9 \\
Nầo tratados & & 0 & 14 & 14 & 0,0 \\
\hline
\end{tabular}

*Critério de cura: negativização sorológica.
Tabela 14 - Proporção de crianças com infecção chagásica crônica que negativaram a sorologia convencional pós tratamento tripanossomicida, por sexo ( seguimento e $\geq 4$ anos) Santa Fé, Argentina, 1976-2002.

\begin{tabular}{lccc}
\hline \multirow{2}{*}{ Sexo } & Total de crianças & \multicolumn{2}{c}{ Sorologia negativa } \\
\cline { 3 - 4 } & $\mathrm{n}^{\circ}$ & $\mathrm{n}^{\circ}$ & $\%$ \\
\hline Feminino & 26 & 15 & 58,0 \\
Masculino & 23 & 14 & 61,0 \\
\hline Total & 49 & 29 & 59,0
\end{tabular}

$\chi^{2}(p>0,05)$

Tabela 16 - Tempo de seguimento de criançasinfectadas chagásicas crônicos segundo droga recebida eresposta ao tratamento, utilizando como critério de cura a negativação sorológica ( Santa Fé, Argentina, 1976-2002).

\begin{tabular}{lrrrrr}
\hline \multirow{2}{*}{$\begin{array}{l}\text { Tempo de seguimentos } \\
\text { (anos) }\end{array}$} & \multicolumn{2}{c}{ Curados } & & \multicolumn{2}{c}{ Năo curados } \\
\cline { 2 - 3 } Benznidazol & média & mediana & & media & mediana \\
\hline Nifurtimox & 13,39 & 13 & & 8,36 & 6 \\
\hline
\end{tabular}




\section{REFERÊNCIAS BIBLIOGRÁFICAS}

1. Altcheh J, Biancardi M, Conca Moreno M, Torres N, Freilij H. Eficacia del tratamiento con nifurtimox en 86 casos de chagas congénito. Revista Medicina (Buenos Aires) 60 ( supl III):80, 2000.

2. Amato Neto V. Etiological treatmentfor infection by Trypanosoma cruzi. Editorial Revista do Instituto de Medicina Tropical de São Paulo 41:211-213, 1999.

3. Andrade ALA, Zicker F, Oliveira RM, Silva SS, Luquetti A, Travassos LR, Almeida IC, Andrade SS, Andrade JG, Martelli CMT. Randomised trial of efficacy of benznidazole in treatment of early Trypanosoma cruzi infection. The Lancet 348:1407-1413, 1996

4. Armitage P, Berry G. Estadística para la investigación biomédica. Doyma, España, 1992.

5. Barclay CA, Cerisola JA, Lugones H, Ledesma O, Silva L, Bouzo G. Aspectos farmacológicos y resultados terapéuticos del benznidazol en el tratamiento de la infección chagásica. La Prensa Médica Argentina 65:239-244, 1978.

6. Britto C, Cardoso A, Silveira C, Maedo V, Fernandes 0. Polymerasa chain reaction (PCR) as a laboratory tool for the evaluation of the parasitological cure in Chagas'disease after specific treatment. Revista Medicina (Buenos Aires) 52:176-178, 1999

7. Cançado JR. Terapéutica específica. In: Dias JCP, Coura JR ( eds) Clínica e Terapêutica da Doença de Chagas, Fundação do Instituto Oswaldo Cruz, Rio de Janeiro, p. 323-351, 1997.

8. Cançado JR. Criteria of Chagas Diseases Cure. Memórias do Instituto Oswaldo Cruz, Rio de Janeiro 94:331-335, 1999.

9. Cançado JR, Brener Z. Terapêutica. In: Brener Z, Andrade Z (eds) Trypanosoma cruzi e Doença de Chagas. Editora Guanabara Koogan, Rio de Janeiro, Brasil, p. 362-424, 1979.

10. Cappa SG, Menes S, Schmuñis G, Szarfman A, Vattuone N, Yanovsky J. La detección de aglutininas específicas en el diagnóstico de la enfermedad de Chagas ( Tripanosomiasis americana). Revista Medicina ( Buenos Aires) 36:364-375, 1976

11. Cerisola JA. Chemotherapy of Chagas infections in man. Scientific Publication Pan American Health Organization № 347, 1977.

12. Cerisola JA, Rohweder R, Segura EL, Del Prado CE, Alvarez M, de Martini GJW. El xenodiagnóstico. Normatización. Institute National of Diagnosis and Investigation of Chagas Disease Dr Mario Fatala Chaben (INDIECH), Buenos Aires, Argentina, 1974.

13. Corral RS, Altcheh JM, Biancardi M, Freilij HL. Determinación de anticuerpos anti-F2/3 en pacientes con Chagas congénito. Revista Medicina (Buenos Aires) 60 ( supl III) : 85-86, 2000.

14. Coura JR, Castro SL. A critical review on Chagas Disease chemotherapy. Memórias do Instituto Oswaldo Cruz 97: 3-24, 2002.

15. Dávila EV, Streiger ML, Bovero NM, Fabbro D. Comparación de 3 reacciones serológicas para infección chagásica. Acta Bioquímica Clínica Latino Americana 16:99-102, 1982.

16. Del Barco M, Streiger M, Arias E, Fabbro D, Amicone N. Respuesta al tratamiento en niños con infección chagásica crónica. Revista Medicina (Buenos Aires) 53( supl I) :78, 1993 .

17. Estani SS, Segura EL. Tratamiento de la infección por Trypanosoma cruzi en fase indeterminada. Experiencia y normatización actual en la Argentina. Revista Medicina (Buenos Aires) 59:166-170, 1999.

18. Estani SS, Segura EL, Ruiz AM, Velazquez E, Porcel BM, Yampotis C. Efficacy of chemoterapy with benznidazole in children in the indeterminate phase of Chagas'disease. American Journal of Tropical Medicine and Hygiene 59:526-529, 1998

19. Freilij H, Altcheh J. Congenital Chagas' disease: diagnostic and clinical aspects. Clinical Infectious Disease 21:551-555, 1995.

20. Grill D, Elizari M, Szarfman A, Urman J, Schmuñis GA. Anticuerpos antiTripanosoma cruzi en recién nacidos normales hijos de madres infectadas. Revista Medicina (Buenos Aires) 36:158, 1976.

21. Jörg ME. Tripanosomiasis Cruzi Humana o enfermedad de Chagas. Actualización de tratamientos. 1/74 Roche Cardiología Año XXIX № 380 Mayo 1974
22. Libonatti E, Manzullo E, Darraidou M, Quiñones G, Morgade S, Libonatti 0 . Seguimiento longitudinal de 4.441 chagásicos crónicos en nueve años. Premio Humberto Ruggero. Asociación Médica Argentina, Buenos Aires, 1979.

23. Madoery RJ, Madoery C. Período intermedio de la enfermedad de Chagas. In: Madoery R, Madoery C, Cámera MI (eds) Actualizaciones en Enfermedad de Chagas, Grafiquil, Organismo Oficial del Congreso Nacional de Medicina, Buenos Aires, p. 51-56, 1993.

24. Ministerio de Salud y Acción Social. Normas para Atención Médica del infectado chagásico. COFESA. Buenos Aires, Argentina, 1983.

25. Ministerio de Salud y Acción Social. Manual para la Atención del paciente chagásico. Secretaría de Programas de Salud. ANLIS. CeNDIE. Instituto Nacional de Parasitología Dr. Mario Fatala Chaben. Servicio Nacional de Chagas Córdoba, (Argentina), p. 15, 1998.

26. Moya P, Paolasso RD, Blanco S, Lapasset M, Sanmartino C, Basso B, Moretti E, Cura D. Tratamiento de la enfermedad de Chagas con nifurtimox durante los primeros meses de vida. Revista Medicina (Buenos Aires) 45:553-558, 1985

27. Orrego LA, Lansetti JC, Bozzini JCM, Martíni CJW. Hemocultivo como método diagnóstico de la enfermedad de Chagas. Revista Medicina (Buenos Aires) 40:56-62, 1980.

28. Ostermayer AL, Rassi A. Diagnosis and treatment of the infection by Trypanosoma cruzi. Memórias do Instituto Oswaldo Cruz, Rio de Janeiro 95( supl II) :37-37, 2000.

29. Produtos Roche SAQ. Industria. Posología según Prospecto de Radanil ${ }^{\circledR}$ (Antichagásico). Especialidad medicinal autorizada por la Secretaría de Estado de Salud Pública. Certificado no 35352, Argentina, 1991.

30. Santos GR, Noshiya AS, Sabino EC, Camone DF, Saez-Alquezar A. An improved, PCR-based strategy for the detection of Trypanosoma cruzi in human blood samples. Annals of Tropical Medical Parasitology 93:689694, 1999.

31. Stephen BH, Cummings Steven R. Diseño de la investigación clínica. Un enfoque epidemiológico. Doyma, España, 1993.

32. Stoppani A0M. Quimioterapia de la enfermedad de Chagas. Revista Medicina (Buenos Aires) 59: 147-165, 1999

33. Storino R, Milei J. Evolución natural y estudios longitudinales. In: Storino R, Milei J, Doyma (eds) Enfermedad de Chagas, Argentina, p.593-604, 1994.

34. Streiger M, Bovero N, Beltramino R, Arias E, del Barco M, Fabbro D. Chagas congénito. Un caso que deja muchas enseñanzas. Revista FABICIB 3:137-142, 1999

35. Streiger ML, Bovero NM, Dávila EV. Reacción de inmunofluorescencia indirecta para el diagnóstico de la infección chagásica. Conservación de improntas. Revista Medicina (Buenos Aires) 40: 250-251, 1980.

36. Streiger ML, del Barco ML, Fabbro DL, Visentín S, Arias ED, Giraldez E, Miglietta H. Infección chagásica al ingreso escolar. Metodología de estudio y experiencia piloto. Acta Bioquímica Clínica Latino Americana 20:139144, 1986.

37. Streiger ML, Fabbro DL, Amicone N, Arias E, Gallo S, Coppoletta G, Velásquez ME. Experiencia de trabajo interdisciplinario entre lo biológico y lo social: cuando lo necesario se hace posible. Revista FABICIB 2:145-149, 1998.

38. Streiger M, Fabbro D, del Barco M, Beltramino R, Bovero N. Chagas congénito en la ciudad de Santa Fe. Diagnóstico y tratamiento. Revista Medicina (Buenos Aires) 55:125-133, 1995.

39. Strout RG. A method for concentrating hemoflagellates. Journal of Parasitology 48:100, 1962.

40. Suasnábar DF, Arias E, Streiger M, del Barco M, Amicone N, Miglietta H. Evaluación de la quimioterapia especifica en infectados chagásicos adultos en fase indeterminada con más de quince años de seguimiento. Revista de la Federación Argentina de Cardiología 30:496-503, 2001.

41. Suasnábar DF, Arias E, Streiger M, Piacenza R, Ingaramo M, del Barco M, Amicone N. Evolutive behavior towards cardiomyopathy of treated (nifurtimox or benznidazole) and untreated chronic chagasic patients. Revista do Instituto de Medicina Tropical de São Paulo 42:99-109, 2000.

42. World Health Organization. Control of Chagas disease. Report of a WHO Expert Committee. Technical Report Series 905, Geneva, 2002. 